\title{
Recursos não-farmacológicos para alívio da dor no trabalho de parto: Relato de experiência e revisão integrativa
}

\author{
Non-pharmacological methods for pain relief during labor: Experience report and an integrative \\ review
}

Recursos no farmacológicos para el alivio del dolor durante el trabajo de parto: Informe de experiencia y revisión

Caroline Tibola

ORCID: https://orcid.org/0000-0003-2350-8977 Universidade Federal do Pampa, Brasil E-mail: carolinetibola@hotmail.com

Mariana Maydana Rivero

ORCID: https://orcid.org/0000-0003-3092-7934 Universidade Federal do Pampa, Brasil

E-mail: mariana_rivero_15@hotmail.com Amanda Fernandes Pacheco ORCID: https://orcid.org/0000-0001-9796-1972 Universidade Federal do Pampa, Brasil E-mail: amandafp2005@hotmail.com

Inaê de Oliveira Marcelo

ORCID: https://orcid.org/0000-0002-8221-113X Universidade Federal do Pampa, Brasil E-mail: inae.oliveiram@hotmail.com

Sara Lima Pereira Correa

ORCID: https://orcid.org/0000-0002-4725-1056 Universidade Federal do Pampa, Brasil E-mail: saracorrea.fisio@hotmail.com Juliana Möbs Canova

ORCID: https://orcid.org/0000-0001-7685-7762 Universidade Federal do Pampa, Brasil E-mail: juliana-mobs@hotmail.com Ruthy Cristina Silva Morais

ORCID: https://orcid.org/0000-0003-1536-4563 Universidade Federal do Pampa, Brasil

E-mail: ruthycmorais@hotmail.com

Pietra de Vargas Minuzzi

ORCID: https://orcid.org/ 0000-0001-9649-345X Universidade Federal do Pampa, Brasil

E-mail: pietraminuzzi@gmail.com

Fabiana Vargas-Ferreira

ORCID: https://orcid.org/0000-0003-3567-4737

Universidade Federal de Minas Gerais, Brasil

E-mail: fabivfer@yahoo.com.br

Fernanda Vargas Ferreira

ORCID: https://orcid.org/0000-0002-2009-3422 Universidade Federal do Pampa, Brasil

E-mail: fernandaferreira@unipampa.edu.br

\section{Resumo}

Introdução: A dor durante o trabalho de parto pode ser modulada por agentes não farmacológicos, todavia, seus mecanismos não estão completamente elucidados. Os objetivos foram identificar evidências científicas sobre recursos não-farmacológicos para o alívio da dor no trabalho de parto em associação a um relato de experiência. Metodologia: Revisão integrativa da literatura realizada através do acesso às bases de dados BVS, Embase e MEDLINE com descritores, respectivamente, do DECS, Emtree e MESH em fevereiro de 2021. Foram incluídos artigos oriundos de pesquisa original, na íntegra, em inglês, português ou espanhol, no recorte temporal de 2014 a 2020 e que apresentassem o uso de recursos não-farmacológicos para alívio da dor em parturientes. Adicionalmente, relata-se uma experiência de extensão vivenciada por discentes do Curso de Fisioterapia em maternidade pública do interior do 
Rio Grande do Sul. Resultados: Encontraram-se 20 artigos que empregaram de forma isolada ou combinada massoterapia, deambulação, posturas verticais, exercícios pélvicos e respiratórios, musicoterapia, bola de parto, banho de aspersão ou de imersão, taping e eletroestimulação transcutânea (EET). A ação de extensão envolveu 13 parturientes que foram assistidas com recursos terapêuticos, além do estímulo à liberdade de movimento e de vocalização. Conclusão: Tais métodos podem ser medidas de conforto na assistência de acordo com a revisão integrativa e com o relato de experiência. Sugere-se que novos estudos sejam realizados, buscando qualificar e fortalecer a abordagem fisioterapêutica no trabalho de parto.

Palavras-chave: Trabalho de parto; Dor do parto; Modalidades de fisioterapia; Revisão.

\begin{abstract}
Introduction: Pain during labor can be modulated by non-pharmacological agents, however, its mechanisms are not fully elucidated. The purposes of this study were to identify scientifical productions in the literature regarding nonpharmacological methods for pain relief during labor in association with an experience report. Methods: It is an integrative review conducted through access to VHL, Embase and MEDLINE databases using the keywords, respectively, from DECS, Emtree e MESH in 2021 february. Full articles in English, Portuguese or Spanish from original researches were included in the time cut from 2015 to 2020, and which presented non-pharmacological methods for pain relief during labor. In addition, this work aimed to describe an undergraduate experience in the Physical Therapy course in a public maternity of a city in the countryside of Rio Grande do Sul (Brazil). Results: Twenty articles highlighting the issue were found which applied massage, walking, vertical positions, breathing exercise technique, pelvic exercise, musicotherapy, birth ball, warm aspersion or immersion, kinesio taping and tanscutaneous electrical stimulation (TENS). Extension program involved 13 parturients who were assisted by, in an isolated and combined manner, with therapeutic methods; in addition, we encouraged freedom of movement and vocalization. Conclusion: These methods bring to the conclusion that may be comfort measures in the assistance according to the integrative review. Further studies are required in order to qualify and strengthen physiotherapeutic approach in labor.
\end{abstract}

Keywords: Labor; Labor pain; Physical therapy Specialty; Revision.

\title{
Resumen
}

Introducción: El dolor durante el trabajo de parto puede ser modulado por agentes no farmacológicos, sin embargo, sus mecanismos no están completamente aclarados. Los objetivos eran identificar la evidencia científica sobre recursos no farmacológicos para el alivio del dolor durante el trabajo de parto en asociación con un informe de experiencia. Método: Revisión integrativa de la literatura realizada a través del acceso a las bases de datos BVS, Embase y MEDLINE con descriptores, respectivamente, de DECS, Emtree y MESH en febrero de 2021. Se incluyeron artículos de investigación original, en su totalidad, en inglés, portugués o español, en el tiempo. marco de 2014 a 2020 y que presentó el uso de recursos no farmacológicos para el alivio del dolor en parturientas. Adicionalmente, reportamos una experiencia de extensión vivida por estudiantes del Curso de Fisioterapia en una maternidad pública en el interior de Rio Grande do Sul. Resultados: Se encontraron 20 artículos que utilizaban, de manera aislada o combinada, terapia de masaje, deambulación, posturas verticales, pélvicas. y ejercicios de respiración, musicoterapia, pelota de reparto, rociado o baño de inmersión, vendaje y electroestimulación transcutánea (TSE). La acción de extensión involucró a 13 parturientas que fueron asistidas con recursos terapéuticos, además de incentivar la libertad de movimiento y vocalización. Conclusión: Por tanto, dichos métodos pueden ser medidas de comodidad en la atención según la revisión integradora. Se sugiere que se realicen más estudios, buscando calificar y fortalecer el abordaje fisioterapéutico en el trabajo de parto.

Palabras clave: Trabajo de parto; Dolor de parto; Modalidades de fisioterapia; Revisión.

\section{Introdução}

O Trabalho de Parto (TP) é um processo fisiológico que envolve uma cascata de alterações mecânicas e hormonais que é usualmente percebido pela gestante como um momento de medo, insegurança e angústia os quais podem intensificar a percepção dolorosa (Félix et al., 2019; Olza et al., 2018).

Com base nas Políticas Públicas voltadas à Saúde da Mulher desde o final da década de 80 tem-se pautado a humanização no TP com vistas a reduzir a medicalização e a artificialização em prol de um parir mais humanizado e natural. Tais premissas corroboram as recomendações da Organização Mundial da (OMS) que contempla uma série de práticas e procedimentos que devem ser adotados para uma melhor qualidade na assistência (Baldisserotto et al., 2016).

Nesse sentido, reitera-se que o TP deve se fundamentar no respeito aos direitos da mulher e da criança, oportunizando o acesso da parturiente a recursos não farmacológicos (MNFs) para o alívio de dor (Thomson et al., 2019). 
A atuação da Fisioterapia em Obstetrícia objetiva aliviar o quadro álgico, promover relaxamento e otimizar o trabalho de parto por meio de condutas como estímulo à deambulação, adoção de posturas verticais, exercícios respiratórios, eletroestimulação transcutânea (EET), massoterapia, termoterapia e banhos de imersão (Bavaresco et al., 2011).

Outrossim, baseado na Campanha da Associação Brasileira de Fisioterapia na Saúde da Mulher (ABRAFISM) - Por Mais Fisioterapeutas nas Maternidades (Ferroli-Fabricio, Mascarenhas, 2020), o artigo objetiva relatar a experiência da assistência fisioterapêutica em uma maternidade de um hospital público. Além do relato, realizou-se uma revisão integrativa sobre recursos não-farmacológicos no alívio da dor durante o trabalho de parto para fundamentação teórica.

\section{Metodologia}

A revisão integrativa objetiva sintetizar resultados obtidos em pesquisas sobre um tema ou questão, de maneira sistemática, ordenada e abrangente. Formulou-se a seguinte questão norteadora: "quais são as evidências científicas sobre o uso de recursos não-farmacológicos durante o trabalho de parto para o alívio da dor?”. Após, seguiram-se as etapas: estabelecimento dos critérios de inclusão; definição das informações a serem extraídas dos artigos; avaliação dos estudos incluídos na revisão; interpretação dos resultados e apresentação da revisão/síntese do conhecimento (Botelho, Cunha, Macedo, 2011).

Para a elaboração da questão da revisão com abordagem qualitativa (Botelho, Cunha, Macedo, 2011), usou-se a estratégia PICO: parturientes (P - População); recursos não-farmacológicos (I - Fenômeno de Interesse); comparação/controle (C - Comparação) e alívio da dor no trabalho de parto (O - Desfecho).

Secundariamente, adotaram-se os critérios de inclusão: pesquisa original com os delineamentos ensaio controlado ou quasi-experimental, nos idiomas espanhol, inglês e português e publicados no recorte temporal entre 2015 e 2020. Esse recorte temporal está sustentado em prévia revisão que incluiu artigos publicados até 2014 (Angelo et al., 2016). Excluíram-se artigos que não tenham investigado o desfecho de dor durante o trabalho de parto e com amostra não exclusiva de parturientes.

As bases de dados escolhidas foram National Library of Medicine (MEDLINE) via portal PubMed, Embase e Portal Regional da Biblioteca Virtual em Saúde (BVS) e o levantamento foi realizado no mês de fevereiro de 2021. Usaram-se as palavras-chave segundo MeSH: a) Birth; b) Parturition; c) Physical Therapy Specialty; d) Physiotherapy Specialty; e) Labor Pain e f) Obstetric Pain. Como termos de Descritores em Ciências da Saúde (DeCs) usaram-se: a) Trabalho de Parto; b) Dor do Parto; c) Dor do Trabalho de Parto; d) Modalidades de Fisioterapia e e) Técnicas de Fisioterapia. No Emtree usaram-se "Birth" OR "Parturition" AND "Physiotherapy" AND "Labor Pain".

Empregaram-se os operadores booleano AND ou OR para a combinação desses termos em todas as bases.

Quanto à extração de informações, elencaram-se: título; ano de publicação; origem; delineamento do estudo; condutas terapêuticas e achados. A busca pelos artigos foi realizada por dois revisores independentes, primeiramente pela leitura do título e após pelo resumo. Por último, foi realizada a leitura do artigo na íntegra pelos dois revisores para a inclusão do artigo; em caso de discordância, o artigo era avaliado por um terceiro revisor.

As bases de dados e as respectivas estratégias de busca são apresentadas no Quadro 1. 
Quadro 1 - Bases de dados e estratégias de busca empregadas na revisão integrativa acerca dos recursos não farmacológicos para alívio da dor em mulheres em trabalho de parto, 2021.

\begin{tabular}{|l|l|}
\hline Base de dados e Portais Eletrônicos & Estratégias de busca \\
\hline MEDLINE & $\begin{array}{l}\text { "Birth" OR "Parturition" AND "Physical Therapy } \\
\text { Specialty" OR "Physiotherapy Specialty" AND "Labor } \\
\text { Pain" OR "Obstetric Pain" }\end{array}$ \\
\hline Portal Regional da BVS & $\begin{array}{l}\text { "Trabalho de Parto" AND "Dor do Parto" OR "Dor do } \\
\text { Trabalho de Parto" AND "Modalidades de Fisioterapia" } \\
\text { OR "Técnicas de Fisioterapia" }\end{array}$ \\
\hline Embase & $\begin{array}{l}\text { "Birth" OR "Parturition" AND "Physiotherapy" AND } \\
\text { "Labor Pain" }\end{array}$ \\
\hline
\end{tabular}

Fonte: Pesquisadores (2021).

\section{Resultados e Discussão}

\subsection{Revisão Integrativa}

Nas buscas nas bases de dados e portais eletrônicos, foram encontradas, inicialmente, 67 produções. Os estudos duplicados foram contabilizados uma única vez. Após a remoção das duplicações, permaneceram 60 produções. Dessas, 38 foram excluídas. Assim, selecionaram-se 20 artigos para leitura na íntegra e avaliação da elegibilidade, os quais resultaram no corpus da revisão integrativa.

O fluxograma (Figura 1) descreve o percurso para a seleção dos artigos e suas respectivas bases de dados.

Figura 1 - Fluxograma da seleção artigos para a revisão integrativa acerca de recursos não-farmacológicos para alívio da dor no trabalho de parto.

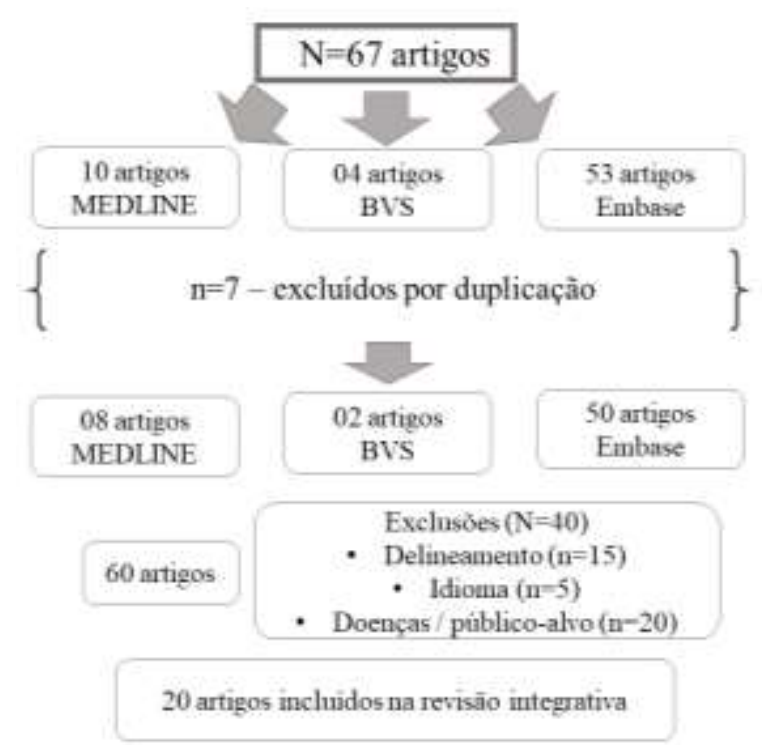

Fonte: Pesquisadores (2021).

No Quadro 2 constam características gerais e no Quadro 3 se apresentam as características específicas dos artigos incluídos na revisão integrativa (ao final). 
Quadro 2 - Distribuição de publicações segundo país, ano de publicação, autor, título e periódico de publicação (N=20).

\begin{tabular}{|c|c|c|c|c|c|}
\hline País & $\begin{array}{c}\text { Ano } \\
\text { Publicação }\end{array}$ & Autor & Título & Periódico & Ordem \\
\hline Brasil & 2018 & Gallo et al & $\begin{array}{l}\text { Sequential application of non- } \\
\text { pharmacological interventions reduces the } \\
\text { severity of labour pain, delays use of } \\
\text { pharmacological analgesia, and improves }\end{array}$ & J Physiother & 1 \\
\hline Turquia & 2020 & $\begin{array}{l}\text { Gönenç, } \\
\text { Terzioğlu }\end{array}$ & $\begin{array}{l}\text { Effects of massage and acupressure on } \\
\text { relieving labor pain, reducing labor time, and } \\
\text { increasing delivery satisfaction }\end{array}$ & J Nurs Res & 2 \\
\hline Índia & 2020 & $\begin{array}{l}\text { Pawale, } \\
\text { Salunkhe }\end{array}$ & $\begin{array}{l}\text { Effectiveness of back massage on pain relief } \\
\text { during first stage oflabor in primi mothers } \\
\text { admitted at a Tertiary care center }\end{array}$ & $\begin{array}{l}\text { J Family Med } \\
\text { Prim Care }\end{array}$ & 3 \\
\hline Egito & 2016 & Zaki & $\begin{array}{l}\text { Effect of pelvic rocking exercise using sitting } \\
\text { position on birth ball during the first stage of } \\
\text { labor on its progress }\end{array}$ & $\begin{array}{l}\text { J Nurs and } \\
\text { Health Science }\end{array}$ & 4 \\
\hline Irã & 2016 & Taavoni et al & $\begin{array}{l}\text { Birth ball or heat therapy? A randomized } \\
\text { controlled trial to compare the effectiveness } \\
\text { of birth ball usage with sacrum-perineal heat } \\
\text { therapy in labor pain management }\end{array}$ & $\begin{array}{l}\text { Complement } \\
\text { Ther Clin Pract }\end{array}$ & 5 \\
\hline Turquia & 2018 & Surucu et al & $\begin{array}{l}\text { The effect of music on pain and anxiety of } \\
\text { women during labour on first time pregnancy: } \\
\text { A study from Turkey }\end{array}$ & $\begin{array}{l}\text { Complement } \\
\text { Ther Clin Pract }\end{array}$ & 6 \\
\hline Turquia & 2020 & $\begin{array}{l}\text { Gönenç, } \\
\text { Dikmen }\end{array}$ & $\begin{array}{c}\text { Effects of Dance and Music on Pain and Fear } \\
\text { During Childbirth }\end{array}$ & $\begin{array}{c}\text { J Obstet } \\
\text { Gynecol } \\
\text { Neonatal Nurs }\end{array}$ & 7 \\
\hline Egito & 2016 & $\begin{array}{l}\text { El-Refaye, El } \\
\text { Nahas, Ghareeb }\end{array}$ & $\begin{array}{c}\text { Effect of kinesio taping therapy combined } \\
\text { with breathing exercises on childbirth } \\
\text { duration and labor pain: a randomized } \\
\text { controlled trial }\end{array}$ & $\begin{array}{l}\text { Bulletin of } \\
\text { Faculty of } \\
\text { Physical } \\
\text { Therapy }\end{array}$ & 8 \\
\hline Brasil & 2019 & Cavalcanti et al & $\begin{array}{l}\text { Terapias complementares no trabalho de } \\
\text { parto: ensaio clínico randomizado }\end{array}$ & $\begin{array}{l}\text { Rev Gaúcha } \\
\text { Enferm }\end{array}$ & 9 \\
\hline Brasil & 2018 & Henrique et al & $\begin{array}{l}\text { Non-pharmacological interventions during } \\
\text { childbirth for pain relief, anxiety, and } \\
\text { neuroendocrine stress parameters: A } \\
\text { randomized controlled trial }\end{array}$ & Int J Nurs Pract & 10 \\
\hline Brasil & 2016 & Santana et al & $\begin{array}{c}\text { Transcutaneous electrical nerve stimulation } \\
\text { (TENS) reduces pain and postpones the need } \\
\text { for pharmacological analgesia during labour: } \\
\text { a randomised trial }\end{array}$ & J Physiother & 11 \\
\hline Polônia & 2018 & Czech et al & $\begin{array}{c}\text { Pharmacological and Non-Pharmacological } \\
\text { Methods of Labour Pain Relief- } \\
\text { Establishment of Effectiveness and } \\
\text { Comparison }\end{array}$ & $\begin{array}{l}\text { Int J Environ } \\
\text { Res Public } \\
\text { Health }\end{array}$ & 12 \\
\hline Irã & 2018 & Makvandi et al & $\begin{array}{l}\text { The Effect of Normal Physiologic Childbirth } \\
\text { on Labor Pain Relief: an Interventional Study } \\
\text { in Mother-Friendly Hospitals }\end{array}$ & $\begin{array}{l}\text { MAEDICA - a J } \\
\text { Clin Med }\end{array}$ & 13 \\
\hline
\end{tabular}


Research, Society and Development, v. 10, n. 7, e18310716446, 2021

(CC BY 4.0) | ISSN 2525-3409 | DOI: http://dx.doi.org/10.33448/rsd-v10i7.16446

\begin{tabular}{|c|c|c|c|c|c|}
\hline Irã & 2017 & Shahoel et al & $\begin{array}{l}\text { The effect of transcutaneous electrical nerve } \\
\text { stimulation on the severity of labor pain } \\
\text { among nulliparous women: A clinical trial }\end{array}$ & $\begin{array}{l}\text { Complement } \\
\text { Ther Clin Pract }\end{array}$ & 14 \\
\hline Irã & 2017 & $\begin{array}{l}\text { Yazdkhasti, } \\
\text { Hanjani, } \\
\text { Tourzani }\end{array}$ & $\begin{array}{l}\text { The Effect of Localized Heat and Cold } \\
\text { Therapy on Pain Intensity, Duration of Phases } \\
\text { of Labor, and Birth Outcomes Among } \\
\text { Primiparous Females: A Randomized, } \\
\text { Controlled Trial }\end{array}$ & Shiraz E-Med J & 15 \\
\hline Irã & 2016 & $\begin{array}{l}\text { Yazdkhasti, } \\
\text { Pirak }\end{array}$ & $\begin{array}{l}\text { The effect of aromatherapy with lavender } \\
\text { essence on severity of labor pain and duration } \\
\text { of labor in primiparous women }\end{array}$ & $\begin{array}{l}\text { Complement } \\
\text { Ther Clin Pract }\end{array}$ & 16 \\
\hline Brasil & 2017 & $\begin{array}{l}\text { Boaviagem et } \\
\text { al }\end{array}$ & $\begin{array}{c}\text { The effectiveness of breathing patterns to } \\
\text { control maternal anxiety during the first } \\
\text { period of labor: A randomized controlled } \\
\text { clinical trial }\end{array}$ & $\begin{array}{l}\text { Complement } \\
\text { Ther Clin Pract }\end{array}$ & 17 \\
\hline Irã & 2015 & $\begin{array}{c}\text { Dehcheshmeh, } \\
\text { Rafiei }\end{array}$ & $\begin{array}{c}\text { Complementary and alternative therapies to } \\
\text { relieve labor pain: A comparative study } \\
\text { between music therapy and Hoku point ice } \\
\text { massage }\end{array}$ & $\begin{array}{l}\text { Complement } \\
\text { Ther Clin Pract }\end{array}$ & 18 \\
\hline Irã & 2018 & Abedi et al & $\begin{array}{l}\text { The Effect of Auriculotherapy on Labor Pain, } \\
\text { Length of Active Phase and Episiotomy Rate } \\
\text { Among Reproductive Aged Women }\end{array}$ & $\begin{array}{c}\text { J Family Reprod } \\
\text { Health }\end{array}$ & 19 \\
\hline Irã & 2020 & Alimoradi et al & $\begin{array}{l}\text { Effects of ear and body acupressure on labor } \\
\text { pain and duration of labor active phase: A } \\
\text { randomized controlled trial }\end{array}$ & $\begin{array}{c}\text { Complement } \\
\text { Ther Med }\end{array}$ & 20 \\
\hline
\end{tabular}

Fonte: Pesquisadores (2021). 
Quadro 3: Características específicas dos artigos da revisão integrativa ( $\mathrm{N}=20)$.

\begin{tabular}{|c|c|c|c|c|c|}
\hline $\mathbf{N}^{\mathbf{0}}$ & Amostragem & Condutas & $\begin{array}{l}\text { Fase } \\
\text { Trabalho de } \\
\text { Parto }\end{array}$ & Instrumentos & Achados \\
\hline 1 & $\begin{array}{c}\text { Primíparas } \\
2 \text { grupos } \\
\text { Experimental ( } \mathrm{n}=39, \text { média } \\
\text { de idade }=21,4 \text { anos }) \\
\text { Controle }(\mathrm{n}=35, \text { média de } \\
\text { idade }=22,4 \text { anos })\end{array}$ & $\begin{array}{c}\text { Experimental: bola de parto, } \\
\text { massagem na região lombar e } \\
\text { banho de aspersão (40 minutos de } \\
\text { cada) } \\
\text { Controle: cuidados usuais (40 } \\
\text { minutos) }\end{array}$ & Latente e ativa & $\begin{array}{l}\text { Escala Visual } \\
\text { Analógica }\end{array}$ & $\begin{array}{l}\text { Grupo experimental: } \\
\text { menor intensidade de } \\
\text { dor que o controle }\end{array}$ \\
\hline 2 & $\begin{array}{c}\text { Primíparas } \\
4 \text { grupos } \\
\text { Experimental } 1 \text { ( } \mathrm{n}=30, \\
\text { média de idade }=23,4 \text { anos }) \\
\text { Experimental } 2 \text { ( } \mathrm{n}=30, \\
\text { média de idade }=24,1 \text { anos }) \\
\text { Experimental } 3 \text { ( } \mathrm{n}=30, \\
\text { média de idade }=23,7 \text { anos }) \\
\text { Controle (n=30, média de } \\
\text { idade }=22,4 \text { anos })\end{array}$ & $\begin{array}{l}\text { Experimentais: } \\
\text { 1) } \begin{array}{c}\text { massagem global ( } 30 \\
\text { minutos) }\end{array} \\
\text { (30 minutos) } \\
\text { acupressão no ponto SP6 } \\
\text { 3) massagem e acupressão (30 } \\
\text { minutos) } \\
\text { 4) Controle: cuidados usuais (30 } \\
\text { minutos) }\end{array}$ & Latente e ativa & $\begin{array}{c}\text { Escala Visual } \\
\text { Analógica }\end{array}$ & $\begin{array}{c}\text { Fase latente: grupos } 1 \\
\text { e } 3 \text { - menor } \\
\text { intensidade de dor que } \\
\text { o controle } \\
\\
\text { Fase ativa: grupos } 1,2 \\
\text { e } 3 \text { - menor } \\
\text { intensidade de dor que } \\
\text { o controle }\end{array}$ \\
\hline 3 & $\begin{array}{c}\text { Primíparas } \\
2 \text { grupos } \\
\text { Experimental }(\mathrm{n}=20, \text { faixa } \\
\text { etária }=22-25 \text { anos }) \\
\text { Controle }(\mathrm{n}=20, \text { faixa } \\
\text { etária }=22-25 \text { anos })\end{array}$ & $\begin{array}{l}\text { Experimental: massagem na região } \\
\text { lombar (10 minutos a cada hora) } \\
\text { Controle: cuidados usuais }\end{array}$ & Latente e ativa & $\begin{array}{c}\text { Escala Visual } \\
\text { Numérica }\end{array}$ & $\begin{array}{l}\text { Grupo experimental: } \\
\text { menor intensidade da } \\
\text { dor que o controle }\end{array}$ \\
\hline 4 & Primíparas & $\begin{array}{c}\text { Experimental: movimentação } \\
\text { pélvica sobre bola de parto (10-20 }\end{array}$ & Latente e ativa & $\begin{array}{l}\text { Escala Visual } \\
\text { Analógica }\end{array}$ & $\begin{array}{l}\text { Grupo experimental: } \\
\text { menor intensidade de }\end{array}$ \\
\hline
\end{tabular}


Research, Society and Development, v. 10, n. 7, e18310716446, 2021

(CC BY 4.0) | ISSN 2525-3409 | DOI: http://dx.doi.org/10.33448/rsd-v10i7.16446

\begin{tabular}{|c|c|c|c|c|c|}
\hline & $\begin{array}{c}2 \text { grupos } \\
\begin{array}{c}\text { Experimental }(\mathrm{n}=40, \text { média } \\
\text { de idade }=26,5 \text { anos })\end{array} \\
\text { Controle }(\mathrm{n}=40, \text { média de } \\
\text { idade }=27,8 \text { anos })\end{array}$ & $\begin{array}{c}\text { minutos) } \\
\text { Controle: cuidados usuais }\end{array}$ & & & dor que o controle \\
\hline 5 & $\begin{array}{c}\text { Primíparas } \\
3 \text { grupos } \\
\text { Experimental } 1 \text { ( } \mathrm{n}=30, \\
\text { média de idade }=24,8 \text { anos) } \\
\text { Experimental } 1 \text { ( } \mathrm{n}=30, \\
\text { média de idade }=24,4 \text { anos) } \\
\text { Controle ( } \mathrm{n}=30, \text { média de } \\
\text { idade }=23,7 \text { anos) }\end{array}$ & $\begin{array}{l}\text { Experimentais: } \\
\text { 1) calor na região sacral e perineal } \\
\text { (30 minutos, no mínimo) } \\
\text { 2) movimentação pélvica sobre bola } \\
\text { de parto (30 minutos, no mínimo) } \\
\text { Controle: cuidados usuais }\end{array}$ & Latente e ativa & $\begin{array}{c}\text { Escala Visual } \\
\text { Analógica }\end{array}$ & $\begin{array}{c}\text { Grupo experimental 1: } \\
\text { menor intensidade de } \\
\text { dor que o controle } \\
\text { Grupo experimental 2: } \\
\text { menor intensidade de } \\
\text { dor nos } 3 \text { momentos } \\
\text { (30, } 60 \text { e } 90 \text { minutos) } \\
\text { que o controle }\end{array}$ \\
\hline 6 & $\begin{array}{c}\text { Primíparas } \\
2 \text { grupos } \\
\text { Experimental ( } \mathrm{n}=25, \text { média } \\
\text { de idade }=22,0 \text { anos }) \\
\text { Controle ( } \mathrm{n}=25, \text { média de } \\
\text { idade }=21,0 \text { anos })\end{array}$ & $\begin{array}{l}\text { Experimental: música ( } 3 \text { horas com } \\
20 \text { minutos de som e } 10 \text { minutos em } \\
\text { silêncio) } \\
\text { Controle: cuidados usuais }\end{array}$ & Ativa & $\begin{array}{c}\text { Escala Visual } \\
\text { Analógica }\end{array}$ & $\begin{array}{c}\text { Grupo experimental 1: } \\
\text { menor intensidade de } \\
\text { dor que o controle na } \\
1^{\mathrm{a}} \text { hora }\end{array}$ \\
\hline 7 & $\begin{array}{c}\text { Primíparas } \\
3 \text { grupos } \\
\text { Experimental } 1(\mathrm{n}=31, \text { faixa } \\
\text { etária }=18-34 \text { anos }) \\
\text { Experimental } 2(\mathrm{n}=30, \text { faixa } \\
\text { etária }=18-34 \text { anos })\end{array}$ & $\begin{array}{l}\text { Experimentais: } \\
\text { 1) dança e música ( } 30 \text { minutos) } \\
\text { 2) música (30 minutos) } \\
\text { Controle: cuidados usuais }\end{array}$ & Ativa & $\begin{array}{c}\text { Escala Visual } \\
\text { Analógica }\end{array}$ & $\begin{array}{c}\text { Grupos experimentais } \\
1 \text { e } 2: \text { menores } \\
\text { intensidades de dor } \\
\text { que o controle }\end{array}$ \\
\hline
\end{tabular}


Research, Society and Development, v. 10, n. 7, e18310716446, 2021

(CC BY 4.0) | ISSN 2525-3409 | DOI: http://dx.doi.org/10.33448/rsd-v10i7.16446

\begin{tabular}{|c|c|c|c|c|c|}
\hline & $\begin{array}{c}\text { Controle }(\mathrm{n}=32 \text {, faixa } \\
\text { etária }=18-34 \text { anos })\end{array}$ & & & & \\
\hline 8 & $\begin{array}{c}\text { Primíparas } \\
2 \text { grupos } \\
\text { Experimental } 1(\mathrm{n}=20, \\
\text { média de idade }=27,5 \text { anos }) \\
\text { Experimental } 2(\mathrm{n}=20, \\
\text { média de idade }=28,2 \text { anos })\end{array}$ & $\begin{array}{l}\text { Experimentais: } \\
\text { 1) exercício respiratório } \\
\text { 2) exercício respiratório e taping na } \\
\text { região lombar e abdominal antero- } \\
\text { inferior }\end{array}$ & Latente e ativa & $\begin{array}{l}\text { Escala Visual } \\
\text { Analógica }\end{array}$ & $\begin{array}{l}\text { Grupo experimental 1: } \\
\text { menor intensidade de } \\
\text { dor que o grupo } \\
\text { experimental } 2\end{array}$ \\
\hline 9 & $\begin{array}{c}\text { Primí/multíparas } \\
3 \text { grupos } \\
\text { Experimental } 1(\mathrm{n}=44, \\
\text { média de idade }=26,0 \text { anos }) \\
\text { Experimental } 2(\mathrm{n}=30, \\
\text { média de idade }=27,2 \text { anos }) \\
\text { Experimental } 3(\mathrm{n}=32, \\
\text { média de idade }=24,5 \text { anos })\end{array}$ & $\begin{array}{l}\text { Experimentais: } \\
\text { 1) banho quente de chuveiro, jato } \\
\text { na região lombossacra, } \\
\text { temperatura }=37^{\circ} \mathrm{C} \text { (30 minutos) } \\
\text { 2) exercício perineal com bola de } \\
\text { parto com propulsão e rotação ( } 30 \\
\text { minutos) } \\
\text { 3) terapia combinada ( } 30 \text { minutos) }\end{array}$ & Ativa & $\begin{array}{c}\text { Escala Visual } \\
\text { Analógica }\end{array}$ & $\begin{array}{l}\text { Todos os grupos: } \\
\text { aumento no escore de } \\
\text { dor, sobretudo no } \\
\text { grupo experimental } 1\end{array}$ \\
\hline 10 & $\begin{array}{c}\text { Primí/multíparas } \\
3 \text { grupos } \\
\text { Experimental } 1 \text { ( } \mathrm{n}=39, \\
\text { média de idade }=26,0 \text { anos }) \\
\text { Experimental } 2(\mathrm{n}=39, \\
\text { média de idade }=27,2 \text { anos }) \\
\text { Experimental } 3(\mathrm{n}=39, \\
\text { média de idade }=24,5 \text { anos })\end{array}$ & $\begin{array}{l}\text { Experimentais: } \\
\text { 1) banho quente de chuveiro, jato } \\
\text { na região lombossacra, } \\
\text { temperatura }=37^{\circ} \mathrm{C} \text { ( } 30 \text { minutos) } \\
\text { 2) exercício perineal com bola de } \\
\text { parto com propulsão e rotação ( } 30 \\
\text { minutos) } \\
\text { 3) terapia combinada ( } 30 \text { minutos) }\end{array}$ & Ativa & $\begin{array}{c}\text { Escala Visual } \\
\text { Analógica }\end{array}$ & $\begin{array}{l}\text { Grupo experimental 2: } \\
\text { menor intensidade de } \\
\text { dor }\end{array}$ \\
\hline 11 & Primíparas & $\begin{array}{c}\text { Experimental: EET, } 2 \text { pares de } \\
\text { eletrodos em T10-L1 e S2-4, } \\
\mathrm{f}=100 \mathrm{~Hz} \text {, largura de pulso }=100 \mathrm{~ms} \text { e } \\
\text { intensidade individual ( } 30 \text { minutos) }\end{array}$ & Ativa & $\begin{array}{c}\text { Escala Visual } \\
\text { Analógica }\end{array}$ & $\begin{array}{c}\text { Grupo experimental: } \\
\text { menor intensidade de } \\
\text { dor que o controle }\end{array}$ \\
\hline
\end{tabular}


Research, Society and Development, v. 10, n. 7, e18310716446, 2021

(CC BY 4.0) | ISSN 2525-3409 | DOI: http://dx.doi.org/10.33448/rsd-v10i7.16446

\begin{tabular}{|c|c|c|c|c|c|}
\hline & $\begin{array}{l}2 \text { grupos } \\
\begin{array}{c}\text { Experimental }(\mathrm{n}=23, \text { média } \\
\text { de idade }=20,4 \text { anos })\end{array} \\
\begin{array}{c}\text { Controle }(\mathrm{n}=23, \text { média de } \\
\text { idade }=20,4 \text { anos })\end{array}\end{array}$ & Controle: cuidados usuais & & & \\
\hline 12 & 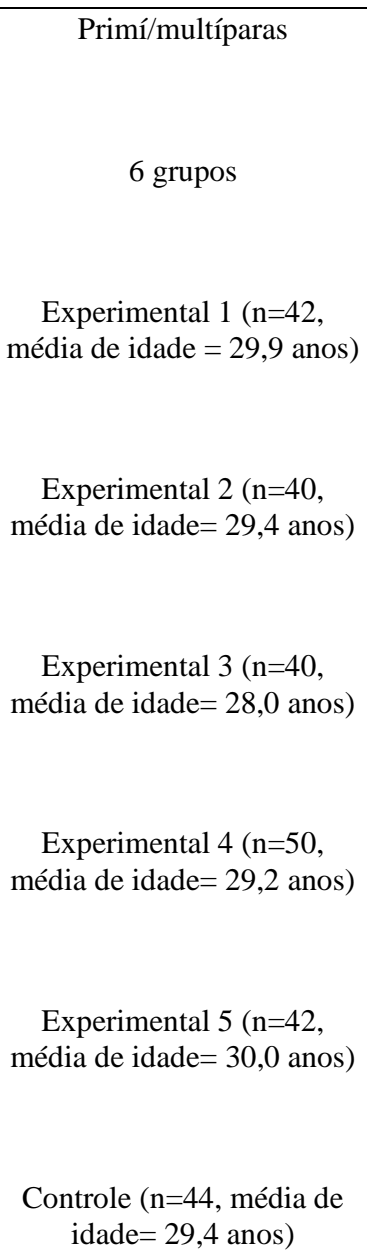 & $\begin{array}{l}\text { Experimentais: } \\
\text { 1) anestesia epidural } \\
\text { 2) banho de aspersão/imersão } \\
\text { 3) óxido nítrico } \\
\text { 4) EET } \\
\text { 5) terapia combinada (EET e óxido } \\
\text { nítrico ou banho de } \\
\text { imersão/aspersão e óxido nítrico) }\end{array}$ & SD & $\begin{array}{c}\text { Escala Visual } \\
\text { Analógica }\end{array}$ & $\begin{array}{l}\text { Grupos experimentais } \\
2 \text { e } 4 \text { não geraram } \\
\text { redução na } \\
\text { intensidade de dor }\end{array}$ \\
\hline 13 & $\begin{array}{l}\text { Primí/multíparas } \\
2 \text { grupos } \\
\text { Experimental }(\mathrm{n}=57, \text { faixa } \\
\text { etária }=18-35 \text { anos }) \\
\text { Controle }(\mathrm{n}=57, \text { faixa } \\
\text { etária }=18-35 \text { anos })\end{array}$ & $\begin{array}{l}\text { Experimental: banho de aspersão } \\
\text { com jato na região abdominal e } \\
\text { temperatura }=36-39^{\circ} \mathrm{C}, \text { movimentos } \\
\text { pélvicos sobre bola de parto ( } 30 \\
\text { minutos) e aromaterapia (essência } \\
\text { de lavanda) } \\
\text { Controle: cuidados usuais }\end{array}$ & Ativa & $\begin{array}{c}\text { Escala Visual } \\
\text { Analógica }\end{array}$ & $\begin{array}{l}\text { Grupo experimental: } \\
\text { menor intensidade de } \\
\text { dor que o controle }\end{array}$ \\
\hline 14 & Primíparas & Experimentais: & Ativa & $\begin{array}{c}\text { Escala Visual } \\
\text { Analógica }\end{array}$ & $\begin{array}{l}\text { Grupo experimental 1: } \\
\text { menor intensidade de } \\
\text { dor que o sham e o }\end{array}$ \\
\hline
\end{tabular}


Research, Society and Development, v. 10, n. 7, e18310716446, 2021

(CC BY 4.0) | ISSN 2525-3409 | DOI: http://dx.doi.org/10.33448/rsd-v10i7.16446

\begin{tabular}{|c|c|c|c|c|c|}
\hline & $\begin{array}{c}3 \text { grupos } \\
\text { Experimental } 1(\mathrm{n}=30, \\
\text { média de idade=26,0 anos) } \\
\text { Experimental } 2(\mathrm{n}=30, \\
\text { média de idade=27,2 anos) } \\
\text { Controle }(\mathrm{n}=30, \text { média de } \\
\text { idade }=24,5 \text { anos })\end{array}$ & $\begin{array}{l}\text { 1) EET, } 2 \text { pares de eletrodos em } \\
\text { T10-L1 e S2-4 (switched-on) } \\
\text { 2) EET-sham, pares de eletrodos } \\
\text { em T10-L1 e S2-4 (switched-off) } \\
\text { Controle: cuidados usuais }\end{array}$ & & & controle \\
\hline 15 & $\begin{array}{c}\text { Primíparas } \\
3 \text { grupos } \\
\text { Experimental } 1(\mathrm{n}=35, \\
\text { média de idade }=25,0 \text { anos }) \\
\text { Experimental } 2 \text { ( } \mathrm{n}=36, \\
\text { média de idade }=24,0 \text { anos }) \\
\text { Controle ( } \mathrm{n}=34, \text { média de } \\
\text { idade }=24,7 \text { anos })\end{array}$ & $\begin{array}{c}\text { Experimentais: } \\
\text { 1) calor, bolsa térmica }\left(38-40^{\circ} \mathrm{C}\right) \\
\text { na região abdominal inferior e } \\
\text { lombar (60 minutos) e após na } \\
\text { região perineal (pelo menos, } 4 \\
\text { minutos) } \\
\text { 2) crioterapia, bolsa de gelo }(10- \\
\text { 15 } \mathrm{C}) \text { na região abdominal inferior } \\
\text { e lombar (10 minutos a cada } 30 \\
\text { minutos) e após na região perineal } \\
(5 \text { minutos a cada } 15 \text { minutos }) \\
\text { Controle: cuidados usuais }\end{array}$ & Ativa & $\begin{array}{l}\text { Questionário de } \\
\text { McGill }\end{array}$ & $\begin{array}{l}\text { Grupos experimentais } \\
1 \text { e } 2: \text { menor } \\
\text { intensidade de dor que } \\
\text { o controle }\end{array}$ \\
\hline 16 & $\begin{array}{c}\text { Primíparas } \\
2 \text { grupos } \\
\text { Experimental ( } \mathrm{n}=60, \text { média } \\
\text { de idade }=18,2 \text { anos }) \\
\text { Controle }(\mathrm{n}=59, \text { média de } \\
\text { idade }=19,1 \text { anos })\end{array}$ & $\begin{array}{l}\text { Experimental: inalação de essência } \\
\text { de lavanda ( } 3 \text { minutos) } \\
\text { Controle: inalação de água destilada } \\
\text { (3 minutos) }\end{array}$ & Ativa & $\begin{array}{c}\text { Escala Visual } \\
\text { Analógica }\end{array}$ & $\begin{array}{l}\text { Grupo experimental: } \\
\text { menor intensidade de } \\
\text { dor que o controle }\end{array}$ \\
\hline 17 & $\begin{array}{c}\text { Primíparas } \\
2 \text { grupos } \\
\text { Experimental ( } \mathrm{n}=67, \text { média } \\
\text { de idade }=21,1 \text { anos) }\end{array}$ & $\begin{array}{l}\text { Experimental: exercício respiratório } \\
\text { Controle: cuidados usuais }\end{array}$ & Ativa & $\begin{array}{c}\text { Escala Visual } \\
\text { Analógica }\end{array}$ & $\begin{array}{l}\text { Não houve efeito } \\
\text { sobre dor }\end{array}$ \\
\hline
\end{tabular}


Research, Society and Development, v. 10, n. 7, e18310716446, 2021

(CC BY 4.0) | ISSN 2525-3409 | DOI: http://dx.doi.org/10.33448/rsd-v10i7.16446

\begin{tabular}{|c|c|c|c|c|c|}
\hline & $\begin{array}{l}\text { Controle ( } \mathrm{n}=73, \text { média de } \\
\text { idade }=20,5 \text { anos })\end{array}$ & & & & \\
\hline 18 & $\begin{array}{c}\text { Primíparas } \\
3 \text { grupos } \\
\text { Experimental } 1 \text { ( } \mathrm{n}=30, \\
\text { média de idade }=21,4 \text { anos }) \\
\text { Experimental } 2 \text { ( } \mathrm{n}=30, \\
\text { média de idade }=22,3 \text { anos) } \\
\text { Controle ( } \mathrm{n}=30, \text { média de } \\
\text { idade }=22,9 \text { anos) }\end{array}$ & $\begin{array}{l}\text { Experimentais: } \\
\text { 1) música (30 minutos) } \\
\begin{array}{c}\text { minutos) } \\
\text { massagem com gelo ( } 20\end{array} \\
\text { Controle: cuidados usuais }\end{array}$ & Ativa & $\begin{array}{c}\text { Escala Visual } \\
\text { Analógica }\end{array}$ & $\begin{array}{c}\text { Grupos experimentais: } \\
\text { menor intensidade de } \\
\text { dor que o controle } \\
\text { Grupo 1: maior } \\
\text { tendência à } \\
\text { diminuição da dor em } \\
\text { relação ao Grupo 2, } \\
\text { porém, sem diferença } \\
\text { estatística }\end{array}$ \\
\hline 19 & $\begin{array}{c}\text { Primíparas } \\
2 \text { grupos } \\
\text { Experimental }(\mathrm{n}=40, \text { média } \\
\text { de idade }=24,7 \text { anos }) \\
\text { Controle }(\mathrm{n}=40, \text { média de } \\
\text { idade }=27,5 \text { anos })\end{array}$ & $\begin{array}{l}\text { Experimental: auriculoterapia nos } \\
\text { pontos Zero, Shen Men, útero, } \\
\text { pelve, abdomen, baço, genitália } \\
\text { externa e encéfalo } \\
\text { Controle: cuidados usuais }\end{array}$ & Ativa & $\begin{array}{c}\text { Escala Visual } \\
\text { Analógica }\end{array}$ & $\begin{array}{l}\text { Grupo experimental: } \\
\text { menor intensidade de } \\
\text { dor que o controle }\end{array}$ \\
\hline 20 & $\begin{array}{c}\text { Primíparas } \\
3 \text { grupos } \\
\text { Experimental } 1 \text { ( } \mathrm{n}=30, \\
\text { média de idade }=24,2 \text { anos) } \\
\text { Experimental } 2 \text { ( } \mathrm{n}=30, \\
\text { média de idade }=24,2 \text { anos) } \\
\text { Controle ( } \mathrm{n}=30, \text { média de } \\
\text { idade }=24,3 \text { anos) }\end{array}$ & $\begin{array}{c}\text { Experimentais: } \\
\text { 1) acupressão nos pontos GB21 } \\
\text { (Jian Jing), GB30 (Huan Tiao), } \\
\text { BL32 (Ciliao), LI4 (Hegu), SP6 } \\
\text { (San Yin Jiao) (2 minutos) } \\
\text { 2) auriculoterapia nos pontos Zero, } \\
\text { genitália, Shen Men, tálamo, } \\
\text { prostaglandina, ocitocina, útero } 1 \text { e } \\
2 \text { acupontos (a cada 30 minutos } \\
\text { compressão de } 30 \text { segundos) } \\
\text { Controle: cuidados usuais }\end{array}$ & Ativa & $\begin{array}{c}\text { Escala Visual } \\
\text { Analógica }\end{array}$ & $\begin{array}{c}\text { Grupos experimentais: } \\
\text { menor intensidade de } \\
\text { dor que o controle }\end{array}$ \\
\hline
\end{tabular}

Legenda: EET= eletroestimulação transcutânea; $\mathrm{SD}=$ sem descrição.

Fonte: Pesquisadores (2021). 


\subsection{Relato de Experiência}

O projeto de extensão foi registrado na instituição sob o nº 10.055 .19 e foi realizado entre junho e dezembro de 2019 em uma maternidade pública de hospital da fronteira oeste do estado do Rio Grande do Sul por uma equipe constituída por discentes do Curso de Fisioterapia da Universidade Federal do Pampa sob orientação de docente que atua na Fisioterapia na Saúde da Mulher / Pélvica. A equipe de extensão envolvia nove acadêmicas que foram divididas em subgrupos de três para início das atividades na maternidade que apresenta sala de pré-parto para mulheres em trabalho de parto e leitos para puérperas que são acompanhadas usualmente por equipe constituída de médico (s), enfermeira (s) e técnica (s). Adicionalmente, discentes de Cursos da Enfermagem e da Medicina também realizam suas práticas no local.

Antes do início das atividades, foram realizadas reuniões com a docente responsável para esclarecer dúvidas e para repassar a rotina. Após a chegada à maternidade, os passos eram: a) diálogo com as enfermeiras e/ou médico (s) para verificar as internações de mulheres de risco habitual, idade gestacional > 37 semanas, em trabalho de parto e com dilatação cervical mínima de 5 centímetros $(\mathrm{cm})$ e b) leitura dos prontuários para extração de informações como idade materna, idade gestacional, número de gestações, tipos de parto, partograma e comorbidades.

As visitas ocorriam duas vezes por semana, nas terças e quartas-feiras, no período da noite em comum acordo com a direção da instituição e a responsável pelo setor da maternidade. Cada visita durava, no mínimo, duas horas, buscando-se atenção integral à (s) parturiente (s). Os procedimentos fisioterapêuticos iniciavam, conforme mencionado, pela interação com a equipe e a leitura dos prontuários. Após, realizava-se a visita à mulher na sala de pré-parto iniciando com a apresentação das discentes e sobre a atuação fisioterapêutica no trabalho de parto.

Todas as parturientes atendidas estavam acompanhadas por pessoa / familiar durante todo o processo de parturição, em conformidade com os preceitos de humanização (de Carvalho et al., 2014). Nesse ponto, importante contextualizar que a realidade local recomenda que o acompanhante seja do sexo feminino para fins de privacidade, já que, o alojamento é coletivo. Caso a parturiente aceitasse participar do atendimento, coletavam-se os sinais vitais (frequência cardíaca, frequência respiratória e pressão arterial), questionava-se a intensidade da dor através da Escala Numérica da Dor (END) de 0 a 10 em que "0 significa ausência" e "10 a pior dor possível", bem como se solicitava a descrição da dor (em pontada, em queimação, pulsátil, em formigamento) e sua localização. Posteriormente, iniciava-se a aplicação de métodos não farmacológicos para o controle da dor, respeitando-se a autonomia da mulher e sua disposição.

A sala de pré-parto possui uma barra de apoio na parede que serviu como suporte à parturiente na posição bípede; sendo sugerido que entre as contrações, ela poderia inclinar-se anteriormente e se quisesse, poderia adotar uma leve flexão de cervical apoiando as mãos na testa junto à parede. Constantemente a (s) discente (s) questionava sobre possíveis queixas como cansaço, dor e tontura, oportunizando constantemente que a parturiente sentasse, se assim fosse desejado. Em pé, por exemplo, a (s) discente (s) orientava a realização de movimentos pélvicos (anteversão, retroversão pélvica, lateralização, circundução) acompanhando a realização como um espelho a fim de que a parturiente tivesse suporte.

Destaca-se que a dor relacionada ao trabalho de parto apresenta múltiplos componentes que podem afetar a sua percepção como experiências prévias, medo, sintomas de ansiedade, etnia, fatores socioculturais e características biológicas (Borges, 2017). Nesse contexto, a Fisioterapia pode utilizar várias estratégias, de forma isolada ou combinada, a fim de gerar o efeito desejado - analgesia.

Assim, nas práticas extensionistas que envolveram 13 parturientes, utilizou-se massoterapia na região lombossacra, mobilidade pélvica, uso de bola de parto ou obstétrica, banho de aspersão, estímulo à deambulação, posturas verticais (eg., bipedestação e sedestação), música e exercícios respiratórios, conforme a progressão do trabalho de parto e o interesse da parturiente. 
O uso da massagem no trabalho de parto parece envolver aspectos emocionais pelo contato físico com a parturiente, redução dos níveis de cortisol e norepinefrina e pelo aumento na liberação de serotonina (Silva Gallo et al., 2013). No contexto da extensão, as parturientes mostravam-se receptivas à massagem na região lombossacra entre as contrações, entretanto, pelas durações e frequências que também eram acompanhadas e quantificadas pela discente (s), algumas participantes não permaneciam por muito tempo em sedestação, sendo possibilitada a livre movimentação.

A escolha da massagem também está embasada na literatura: a) ensaio clínico randomizado avaliou o efeito de uma intervenção constituída por exercícios na bola de parto, massagem lombossacral e banho de aspersão sobre a percepção dolorosa. O grupo experimental, em relação ao grupo controle, teve menor severidade da dor (Gallo et al., 2018), b) estudo comparativo entre grupos que receberam massagem, acupressão ou tratamento combinado evidenciou que a massagem foi mais efetiva na redução da dor em contraste à acupressão (Gönenç, Terzioğlu, 2020) e c) pesquisa comparativa entre o grupo intervenção - massagem e o grupo controle - rotina hospitalar mostrou que os escores de dor foram menores no grupo da massagem (Pawale, Salunkhe, 2020).

O uso de bola de parto também foi empregado para fins terapêuticos e de ludicidade, estimulando a sedestação e a movimentação. Na extensão, quando sentada, atentou-se para que a parturiente não se posicionasse sobre o sacro, pois, os movimentos de contra-nutação e nutação realizados pela articulação sacroilíaca podem afetar significativamente o diâmetro pélvico, especificamente, a entrada pélvica em até 10mm (Desseauve et al., 2017). Movimentos pélvicos (anteversão, retroversão pélvica, lateralização, circundução), em bipedestação ou em sedestação sobre a bola de parto (obstétrica ou suíça) servem para facilitar a descida e a rotação fetais, otimizando assim, o progresso do trabalho de parto (Henrique et al., 2018).

Pela revisão integrativa encontraram-se: a) estudo investigou o efeito da movimentação pélvica na bola de parto e o escore da dor foi menor no grupo intervenção em comparação ao controle (orientações de rotina) (Zaky, 2016) e b) pesquisa comparou os efeitos do calor, da bola de parto ou do controle em 90 parturientes. $\mathrm{O}$ grupo da bola de parto apresentou menores escores de dor em comparação ao controle (Taavoni et al, 2016).

A musicoterapia tem sido apontada como promotora de analgesia, provavelmente, por uma associação de mecanismos que afetam a modulação nociceptiva que seriam o contextual (eg., crenças, expectativas), o cognitivo (eg., atenção, distração), o emocional / o humor (eg., ansiedade, excitação), a liberação de neurotransmissores como opioides endógenos e as características da música (eg., tempo, modo, estrutura) (Lunde et al., 2019).

$\mathrm{Na}$ ação de extensão oferecíamos à parturiente a adoção de música ao longo de atendimento, sendo possibilitada a livre escolha do gênero musical. Atentamos para que a música fosse em intensidade o suficiente para permitir o diálogo e a interação com a equipe. Embora a musicoterapia seja viável como método não farmacológico para alívio da dor, a literatura é escassa e apresenta baixa qualidade metodológica, conforme evidencia recente revisão sistemática (Smith et al., 2018). Assim, na revisão integrativa, encontraram-se dois estudos sobre o tema: a) pesquisa avaliou o efeito de música clássica turca sobre a intensidade da dor sendo observado que após a primeira hora as mulheres indicaram alívio álgico (Surucu et al., 2018) e b) ensaio clínico comparou três grupos (música, dança, combinado) e no qual se observou que os grupos da música e da combinação tiveram uma redução significativa na intensidade dolorosa (Gönenç, Dikmen, 2020).

$\mathrm{O}$ banho de aspersão, especialmente, água morna - quente a $37^{\circ} \mathrm{C}$ está associado à liberação aumentada de endorfina e ao relaxamento da musculatura (Benfield et al., 2010). Na sala de pré-parto usou-se o chuveiro, sendo que, as parturientes poderiam ficar sentadas ou em pé, conforme a vontade. Esse recurso foi um dos preferidos pelas participantes pela sensação de alívio proporcionada pela água; além disso, não houve limite de tempo para a permanência. Os achados da revisão integrativa foram: a) estudo com 128 parturientes foram agrupadas em banho quente de chuveiro na região lombar, ou exercícios perineais na bola de parto ou terapia combinada. Para todos os grupos houve aumento nos escores de percepção de dor, especialmente 
para o primeiro grupo (Cavalcanti et al, 2019) e b) de três grupos (banho quente, bola de parto ou terapia combinada), somente o grupo que usou bola de parto reportou menor escore de dor (Henrique et al, 2018).

As técnicas respiratórias foram adotadas ao longo de todos os atendimentos, buscando-se primordialmente que as parturientes respirassem em um ritmo natural, considerando que esse método não farmacológico se relaciona a um relaxamento, a um aumento na tolerância à dor e a uma redução nos níveis de ansiedade (Vakilian, Keramat, 2013). Ademais, a adoção de padrões respiratórios aumenta a oxigenação materno-fetal e promove satisfação com o processo de parturição (De Araújo et al., 2018).

Na ação de extensão, estimulou-se padrão com respirações lentas e profundas que parece contribuir com a regulação das emoções, provavelmente, por diminuir a ativação da amígdala enquanto se incrementa a integração entre essa e o córtex pré-frontal durante emoções negativas (eg., medo, tensão) (Campanelli et al., 2020). Adicionalmente, durante as contrações, solicitou-se que a parturiente não realizasse por tempo prolongado a Manobra de Valsalva que tem sido associada a uma redução no pH venoso umbilical e no fluxo uteroplacentário (Lemos et al., 2011). Na revisão integrativa: a) pesquisa avaliou o efeito de exercícios respiratórios com ou sem kinesiotaping na região lombar, tendo-se como resultado favorável o grupo com tratamento combinado (El-Refaye et al., 2016) e b) estudo comparativo entre exercícios respiratórios versus controle não apontou efeito sobre a dor no trabalho de parto (Boaviagem et al, 2017).

A deambulação, assim como posições verticais se mostraram superiores às posições clássicas (litotomia, decúbito dorsal) no que tange ao estímulo às contrações uterinas, além de gerar maior conforto materno e acelerar a dilatação cervical (Regaya et al., 2010). Assim, na ação de extensão, se estimulou a deambulação no alojamento e/ou no corredor do setor acompanhada por discente (s). Embora não houvesse um limite de tempo, a duração da deambulação variava entre 10 e 15 minutos conforme a vontade da parturiente. Também se promoveram posturas verticalizadas como bipedestação e sedestação em poltrona / cadeira ou na bola de parto que estão em consonância com as recomendações quanto aos cuidados intraparto da OMS (WHO, 2018). Entre as contrações, a gestante era orientada a sentar-se e a adotar uma inclinação do tronco, o que promovia alívio de dor na região lombossacra que parece responder à hiper lassidão ligamentar por influência hormonal na gestação (eg., progesterona, relaxina) (Kiapour et al., 2020).

Embora na ação de extensão não tenha sido aplicada Estimulação Elétrica Transcutânea (EET), esse recurso foi citado na revisão integrativa: a) estudo mostrou que houve significativa redução na intensidade da dor no grupo do EET (Santana et al, 2016); b) ensaio clínico avaliou o efeito de recursos farmacológicos versus recursos não-farmacológicos (EET, banho de aspersão ou imersão) cujo resultado foi que o EET e o banho não reduziram a intensidade da dor entre a linha basal e a intervenção (Czech et al, 2018) e c) estudo com grupos - a média na severidade dor após 1 hora foi menor no grupo do EET em relação ao grupo controle, porém, sem significância estatística (Shahoei et al, 2017). Os resultados conflitantes podem ser derivados dos parâmetros utilizados na aplicação da EET, da fase (latente vs ativa) e também da percepção da dor.

Também, embora não se tenha empregado crioterapia na extensão, encontraram-se publicações: a) estudo comparativo entre música (A), massagem com gelo (B) ou cuidados gerais (C) encontrou menor intensidade da dor nos dois primeiros grupos em comparação ao controle, porém, entre o A e o B não houve diferença estatística (Dehcheshmeh, Rafiei, 2015). Similarmente, pesquisa comparou três intervenções (crioterapia, calor ou controle) com resultados favoráveis à termoterapia (crioterapia ou calor) (Yazdkhasti, Hanjani, Tourzani, 2018).

A revisão integrativa apontou o uso de recursos da Medicina Tradicional Chinesa (MTC) como auriculoterapia / acupressão que pertencem às Práticas Integrativas e Complementares em Saúde (PICS) cujas ações estão atreladas à Política Nacional de Práticas Integrativas e Complementares em Saúde (PNPICS) e ao Sistema Único de Saúde (SUS) (Brasil, 2006), 
contudo, tal recurso não foi empregado na ação de extensão. Os estudos apontaram efeitos positivos da auriculoterapia na dor em comparação ao controle (Abedi et al, 2017), bem como da auriculoterapia ou da acupressão (Alimoradi et al, 2020).

Um ponto a se destacar envolve o ambiente da maternidade, uma vez que, se a parturiente sentir medo, ocorrerá a liberação de substâncias químicas relacionadas ao estresse que poderá afetar o hormônio ocitocina, resultando em incoordenação na contratilidade uterina (Priddis et al., 2012). Dessa forma, na ação de extensão, se oferecia à gestante a possibilidade de diminuir a luminosidade na sala de pré-parto a fim de promover relaxamento; além de música, conforme mencionado anteriormente. Além disso, durante os atendimentos se buscou acolher, evitar o excesso de atividades para prevenção de fadiga materna, usar linguagem acessível e respeitar as vocalizações e os silêncios que permeiam a parturição em respeito à subjetividade da mulher e seu processo.

Nesse contexto, embora não tenha sido ofertada na extensão, a revisão integrativa apontou como recurso a aromaterapia, que também faz parte das PICS, mencionada previamente, através de dois estudos: a) grupo experimental (óleo essencial de lavanda) versus controle resultou em diferença estatisticamente significante na intensidade da dor em prol do grupo da aromaterapia (Yazdkhasti, Pirak, 2016) e b) terapia combinada entre banho de aspersão, movimentação pélvica na bola de parto e aromaterapia (lavanda) resultou em menor intensidade de dor que no grupo controle (Makvandi et al, 2018).

Destaca-se também que a dinâmica para cada parturiente atendida foi flexibilizada de acordo com a rotina hospitalar que envolvia avaliação da dilatação cervical e aferição da frequência cardíaca fetal, o que também foi uma oportunidade de aprendizado para a (s) discente (s). Adicionalmente, quanto à extensão, deve-se comentar que: a) houve uma baixa demanda de parturientes; b) somente uma (1) parturiente fez uso de medicamento para induzir o parto, o que inviabilizou a continuidade da assistência; c) a maioria das participantes não conhecia o papel da Fisioterapia em Obstetrícia - Trabalho de Parto; d) três mulheres não aceitaram a abordagem fisioterapêutica; e) o exercício de agachamento na barra foi relatado como gerador de cansaço e f) o comportamento / a disposição era variável, possivelmente, pelo próprio trabalho de parto que envolve dor, preocupação e, infelizmente, desinformação sobre a parturição.

\section{Considerações Finais}

O emprego dos recursos não-farmacológicos para alívio da dor no trabalho de parto tem se evidenciado cada vez mais promissor, conforme apontaram as evidências científicas e a experiência relatada na extensão universitária. Destaca-se que os recursos devem ser ofertados à parturiente, respeitando-se a autonomia e a preferência, uma vez que, a abordagem fisioterapêutica deve se alinhar à atenuação da tríade dor-medo-tensão.

Em concordância com a revisão integrada, os recursos terapêuticos mais citados e que foram aplicados na extensão universitária foram estímulo ao movimento (eg., deambulação), posturas verticalizadas (eg., sedestação), exercício respiratório, uso de bola de parto, massagem, música e banho de aspersão; especialmente, o último que gerou maior feedback positivo das parturientes.

Além dos benefícios às parturientes e do enriquecimento acadêmico que o projeto de extensão proporcionou, a possibilidade de disseminar informações quanto à atuação do fisioterapeuta em obstetrícia se mostrou bastante relevante. Outrossim, entende-se que se trata de uma área da Fisioterapia ainda negligenciada pelo grande público e, por vezes, pouco explorada pelos próprios profissionais.

Por fim, a revisão integrativa instiga a realização de novos estudos que abordem, por exemplo, o uso de técnicas respiratórias no trabalho de parto; em associação a um maior rigor metodológico, os quais podem contribuir para o alívio da dor sob o prisma da humanização no processo de parturição. 


\section{Agradecimentos}

Os autores expressam profunda gratidão às participantes por seu tempo, disponibilidade e pela oportunidade de participar de um momento único cuja abordagem fisioterapêutica deve estimular o protagonismo da mulher/gestante durante a parturição. Também agradecem aos membros do Grupo de Estudos e Pesquisa em Fisioterapia e Saúde Pélvica (GEPEFISP).

\section{Referências}

Abedi, P; Rastegar, H;Valiani, M; Saadati, N. (2017). The Effect of Auriculotherapy on Labor Pain, Length of Active Phase and Episiotomy Rate Among Reproductive Aged Women. J Family Reprod Health. Dec;11(4):185-190. PMC6168759.

Alimoradi, Z; Kazemi, F; Gorji, M; Valiani, M. Effects of ear and body acupressure on labor pain and duration of labor active phase: A randomized controlled trial. (2020). Complement Ther Med. Jun; 51:102413. https://doi: 10.1016/j.ctim.2020.102413.

Angelo, P. H. M et al. Recursos não farmacológicos: atuação da fisioterapia no trabalho de parto, uma revisão sistemática. (2016). Fisioterapia Brasil;17(3):285-292. https://doi.org/10.33233/fb.v17i3.489.

Araújo, A. E., Delgado, A., Boaviagem, A., Lemos, A. (2018). Prescription of breathing orientations given by the healthcare team during labor: A crosssectional study. Mundo Da Saude, 42(3), 628-641. https://doi.org/10.15343/0104-7809.20184203628641.

Baldisserotto, M. L., Theme Filha, M. M., Da Gama, S. G. N. (2016). Good practices according to WHO's recommendation for normal labor and birth and women's assessment of the care received: The "birth in Brazil" national research study, 2011/2012. Reproductive Health, 13(Suppl 3). https://doi.org/10.1186/s12978-016-0233-x.

Bavaresco, G. Z., de Souza, R. S. O., Almeica, B., Sabatino, J. H., Dias, M. (2011). O fisioterapeuta como profissional de suporte à parturiente. Ciencia e Saude Coletiva, 16(7), 3259-3266. https://doi.org/10.1590/S1413-81232011000800025.

Boaviagem, A et al. (2017). The effectiveness of breathing patterns to control maternal anxiety during the first period of labor: A randomized controlled clinical trial. Complement Ther Clin Pract. 2017 Feb; 26:30-35. https://doi: 10.1016/j.ctcp.2016.11.004.

Borges, C. (2017). Labor Pain: Perception of the Parturient and Midwife Evaluation. American Journal of Nursing Science, 6(2), 80. https://doi.org/10.11648/j.ajns.20170602.12 ISSN 1980-5756.

Botelho, L. L. R; Cunha, C.C. A.; Macedo, M. (2011). O método da revisão integrativa nos estudos organizacionais. Gestão e Sociedade· Belo Horizonte, v.5, n. 11, p. 121-136.

Brasil. Ministério da Saúde. Política nacional de práticas integrativas e complementares no SUS - PNPIC-SUS: atitude de ampliação de acesso. Brasília: Ministério da Saúde, 2006. (Série B. Textos Básicos de Saúde).

Campanelli, S., Lopes Tort, A., Lobão-Soares, B. (2020). Pranayamas and their neurophysiological effects. International Journal of Yoga, 13(3), 183. https://doi.org/10.4103/ijoy.ijoy_91_19.

Carvalho, V. F., Kerber, N. P. da C., de Azambuja, E. P., Bueno, F. F., da Silveira, R. S., de Barros, A. M. (2014). Rights of parturients: Adolescents' knowledge and that of their companion. Saude e Sociedade, 23(2), 572-581. https://doi.org/10.1590/S0104-12902014000200017.

Cavalcanti, A.C.V, Henrique, A. J, Brasil, C. M, Gabrielloni, M. C, Barbieri, M. Terapias complementares no trabalho de parto: ensaio clínico randomizado. Rev Gaúcha Enferm. 2019;40:e20190026. 80. https://doi.org/10.1590/1983-1447.2019.20190026.

Czech, I; Fuchs, P; Lorek, M; Tobolska-Lorek, D; Drosdzol-Cop, A; Sikora, J. Pharmacological and Non-Pharmacological Methods of Labour Pain ReliefEstablishment of Effectiveness and Comparison. (2018). Int J Environ Res Public Health. Dec 9;15(12):2792. https://doi.org/ 10.3390/ijerph15122792.

Desseauve, D., Fradet, L., Lacouture, P., Pierre, F. (2017). Position for labor and birth: State of knowledge and biomechanical perspectives. In European Journal of Obstetrics and Gynecology and Reproductive Biology (Vol. 208, pp. 46-54). Elsevier Ireland Ltd. https://doi.org/10.1016/j.ejogrb.2016.11.006.

El-Refaye, G., El Nahas, E., Ghareeb, H. (2016). Effect of kinesio taping therapy combined with breathing exercises on childbirth duration and labor pain: a randomized controlled trial. Bulletin of Faculty of Physical Therapy, 21(1), 23. https://doi.org/10.4103/1110-6611.188026.

Benfield, R.D; Hortobágyi, T; Tanner, C. J; Swanson, M; Heitkemper, M.M; Newton, E. R. (2010). The Effects of Hydrotherapy on Anxiety, Pain, Neuroendocrine Responses, and Contraction Dynamics During Labor. Bone, 23(1), 1-7. https://doi.org/10.1177/1099800410361535.

Dehcheshmeh, F. S; Rafiei, H. Complementary and alternative therapies to relieve labor pain: A comparative study between music therapy and Hoku point ice massage. Complement Ther Clin Pract Nov;21(4):229-32. https://doi.org/ 10.1016/j.ctcp.2015.09.002.

Félix, H. C. R., Corrêa, C. C., Matias, T. G. da C., Parreira, B. D. M., Paschoini, M. C., Ruiz, M. T. (2019). The signs of alert and labor: Knowledge among pregnant women. Revista Brasileira de Saude Materno Infantil, 19(2), 335-341. https://doi.org/10.1590/1806-93042019000200005.

Ferroli-fabricio, A. M., Mascarenhas, L. R. (n.d.). Por mais Fisioterapeutas nas Maternidades.

Silva Gallo R.B., Santana L.S., Jorge Ferreira C.H., Marcolin A.C., PoliNeto O.B., Duarte G., Quintana S.M. (2013). Massage reduced severity of pain during labour: A randomised trial. Journal of Physiotherapy. 59:2 (109-116). https://doi.org/ 10.1016/S1836-9553(13)70163-2. 
Gallo, R. B. S., Santana, L. S., Marcolin, A. C., Quintana, S. M. (2014). Swiss ball to relieve pain of primiparous in active labor. Revista Dor, 15(4), 253-255. https://doi.org/10.5935/1806-0013.20140054.

Gallo, R., Santana, L., Marcolin, A., G. D. J. (2018). Sequential application of non-pharmacological interventions reduces the severity of labour pain, delays use of pharmacological analgesia, and improves some obstetric outcomes: a randomised trial. J Physiother. Jan;64(1):33-40. https://doi.org/ 10.1016/j.jphys.2017.11.014.

Gokyildiz Surucu, S., Ozturk, M., Avcibay Vurgec, B., Alan, S., Akbas, M. (2018). The effect of music on pain and anxiety of women during labour on first time pregnancy: A study from Turkey. Complementary Therapies in Clinical Practice, 30, 96-102. https://doi.org/10.1016/j.ctcp.2017.12.015.

Gönenç, İ. M., Dikmen, H. A. (2020). Effects of Dance and Music on Pain and Fear During Childbirth. JOGNN - Journal of Obstetric, Gynecologic, and Neonatal Nursing, 49(2), 144-153. https://doi.org/10.1016/j.jogn.2019.12.005.

Gönenç, I. M., Terzioğlu, F. (2020). Effects of massage and acupressure on relieving labor pain, reducing labor time, and increasing delivery satisfaction. Journal of Nursing Research, 28(1), 1-9. https://doi.org/10.1097/jnr.0000000000000344.

Henrique, A. J., Gabrielloni, M. C., Rodney, P., Barbieri, M. (2018). Non-pharmacological interventions during childbirth for pain relief, anxiety, and neuroendocrine stress parameters: A randomized controlled trial. International Journal of Nursing Practice, 24(3), 1-8. https://doi.org/10.1111/ijn.12642.

Kiapour, A., Joukar, A., Elgafy, H., Erbulut, D. U., Agarwal, A. K., \& Goel, V. K. (2020). Biomechanics of the sacroiliac joint: Anatomy, function, biomechanics, sexual dimorphism, and causes of pain. International Journal of Spine Surgery, 14, S3-S13. https://doi.org/10.14444/6077.

Lemos, A., Dean, E., \& de Andrade, A. D. (2011). The Valsalva maneuver duration during labor expulsive stage: Repercussions on the maternal and neonatal birth condition. Revista Brasileira de Fisioterapia, 15(1), 66-72. https://doi.org/10.1590/S1413-35552011000100012.

Lunde, S. J., Vuust, P., Garza-Villarreal, E. A., \& Vase, L. (2019). Music-induced analgesia: How does music relieve pain? Pain, 160(5), 989-993. https://doi.org/10.1097/j.pain.0000000000001452.

Makvandi, S; Mirzaiinajmabadi, K; Tehranian, N; Esmily, H; Mirteimoori, M. The Effect of Normal Physiologic Childbirth on Labor Pain Relief: an Interventional Study in Mother-Friendly Hospitals. (2018). Maedica (Bucur). Dec; 13(4): 286-293. https://doi: 10.26574/maedica.2018.13.4.286

Olza, I., Leahy-Warren, P., Benyamini, Y., Kazmierczak, M., Karlsdottir, S. I., Spyridou, A., Crespo-Mirasol, E., Takács, L., Hall, P. J., Murphy, M., Jonsdottir, S. S., Downe, S., \& Nieuwenhuijze, M. J. (2018). Women's psychological experiences of physiological childbirth: A meta-synthesis. BMJ Open, 8(10), 1-11. https://doi.org/10.1136/bmjopen-2017-020347.

Pawale, M. P; Salunkhe, J.A. Effectiveness of back massage on pain relief during first stage oflabor in primi mothers admitted at a Tertiary care center. (2020). J Family Med Prim Care. 9(12): 5933-5938. https://doi.org/ 10.4103/jfmpc.jfmpc_1189_20: 10.4103/jfmpc.jfmpc_1189_20.

Priddis, H., Dahlen, H., Schmied, V. (2012). What are the facilitators, inhibitors, and implications of birth positioning? A review of the literature. Women and Birth, 25(3), 100-106. https://doi.org/10.1016/j.wombi.2011.05.001.

Regaya, L. Ben, Fatnassi, R., Khlifi, A., Fékih, M., Kebaili, S., Soltan, K., Khairi, H., Hidar, S. (2010). Intérêt de la déambulation au cours du travail obstétrical: étude prospective randomisée de 200 cas. Journal de Gynecologie Obstetrique et Biologie de La Reproduction, 39(8), 656-662. https://doi.org/10.1016/j.jgyn.2010.06.007.

Santana, L. C.; Gallo, R. B. S; Ferreira, C. H. J.; Duarte, G., Quintana, S. M.Q; Marcolin, A.C. Transcutaneous electrical nerve stimulation (TENS) reduces pain and postpones the need for pharmacological analgesia during labour: a randomised trial. (2016). J Physiother Jan;62(1):29-34. https://doi.org/ 10.1016/j.jphys.2015.11.002.

Silva, Gallo, R. B., Santana, L. S., Jorge Ferreira, C. H., Marcolin, A. C., PoliNeto, O. B., Duarte, G., Quintana, S. M. (2013). Massage reduced severity of pain during labour: A randomised trial. In Journal of Physiotherapy (Vol. 59, Issue 2, pp. 109-116). https://doi.org/10.1016/S1836-9553(13)70163-2.

Shahoei, R; Shahghebi, S; Rezaei, M; Naqshbandi, S. (2017). The effect of transcutaneous electrical nerve stimulation on the severity of labor pain among nulliparous women: A clinical trial. Complement Ther Clin Pract.Aug;28:176-180. https://doi: 10.1016/j.ctcp.2017.05.004.

Smith, C. A., Levett, K. M., Collins, C. T., Dahlen, H. G., Ee, C. C., Suganuma, M. (2018). Massage, reflexology and other manual methods for pain management in labour. In Cochrane Database of Systematic Reviews (Vol. 2018, Issue 3). John Wiley and Sons Ltd. https://doi.org/10.1002/14651858.CD009290.pub3.

Surucu, S.G; Ozturk, M; Vurgec, B.A, Alan, S, Akbas, M. The effect of music on pain and anxiety of women in labor during their first pregnancy: A study from Turkey. (2018). Complementary Therapies in Clinical Practice (2018), doi: 10.1016/j.ctcp.2017.12.015.

Taavoni, S, Sheikhan, F, Abdolahian, S, Ghavi, F. Birth ball or heat therapy? A randomized controlled trial to compare the effectiveness of birth ball usage with sacrum-perineal heat therapy in labor pain management. (2016). Complementary Therapies in Clinical Practice 24 99e102. https://doi.org/ 10.1016/j.ctcp.2016.04.001.

Thomson, G., Feeley, C., Moran, V. H., Downe, S., Oladapo, O. T. (2019). Women's experiences of pharmacological and non-pharmacological pain relief methods for labour and childbirth: A qualitative systematic review. Reproductive Health, 16(1). https://doi.org/10.1186/s12978-019-0735-4.

Vakilian, K., Keramat, A. (2013). The Effect of the Breathing Technique With and Without Aromatherapy on the Length of the Active Phase and Second Stage of Labor. In Nursing and Midwifery Studies (Vol. 1, Issue 3, pp. 115-119). https://doi.org/10.5812/nms.9886.

WHO. (2018). WHO recommendations: Intrapartum care for a positive childbirth experience. Transforming care of women and babies for improved health and well-being Executive summary. WHO Recommendations: Intrapartum Care for a Positive Childbirth Experience., 1-8. https://apps.who.int/iris/bitstream/handle/10665/272447/WHO-RHR-18.12-eng.pdf. 
Research, Society and Development, v. 10, n. 7, e18310716446, 2021

(CC BY 4.0) | ISSN 2525-3409 | DOI: http://dx.doi.org/10.33448/rsd-v10i7.16446

Yazdkhasti, M; Pirak, A. (2016) The effect of aromatherapy with lavender essence on severity of labor pain and duration of labor in primiparous women. Complement Ther Clin Pract. Nov; 25:81-86. https://doi.org/ 10.1016/j.ctcp.2016.08.008.

Yazdkhasti, M; Hanjani, SM; TourzanI, ZM. (2018). The Effect of Localized Heat and Cold Therapy on Pain Intensity, Duration of Phases of Labor, and Birth Outcomes Among Primiparous Females: A Randomized, Controlled Trial. Shiraz E-Med J.; 19(8):e65501.

Zaky, HN. (2016). Effect of pelvic rocking exercise using sitting position on birth ball during the first stage of labor on its progress. IOSR Journal of Nursing and Health Science, 05(04), 19-27. https://doi.org/10.9790/1959-0504031927. 